

\title{
PERANAN PROGRAM SERTIFIKAT UTZ TERHADAP PENINGKATAN PRODUKSI DAN PENDAPATAN PETANI KAKAO DI KABUPATEN JEMBRANA PROVINSI BALI
}

\section{(The Role of UTZ Certified Program on Increasing on Increasing Production and Income of Cocoa Farmers in Jembrana Regency, Bali Province)}

\author{
Windi Arihta Ginting, I.G. A.A. Ambarawati, Ida Ayu Listia Dewi \\ Program Studi Agribisnis, Fakultas Pertanian, Universitas Udayana \\ Jalan PB Sudirman Denpasar 80232 \\ Email: windiarihtaginting@gmail.com
}

Diterima15 April 2019, disetujui 30 Juli 2019

\begin{abstract}
ABSTRAK
Indonesia merupakan penghasil kakao ketiga di dunia. Komoditi kakao Indonesia sangat berpotensi untuk dikembangkan dari segi kuantitas namun dari segi kualitas dinilai masih rendah untuk pasar dunia terutama Eropa. Salah satu program yang dapat mendorong produksi dan kualitas kakao adalah melalui sertifikasi pertanian berkelanjutan yaitu UTZ Certified. Salah satu pemegang sertifikat UTZ di Indonesia adalah Koperasi Kerta Semana Samaniya di Kabupaten Jembrana. Tujuan dari penelitian ini adalah untuk mengetahui perbedaan produksi dan pendapatan usahatani kakao bersertifikat UTZ dan yang tidak mengikuti program sertifikat UTZ di Kabupaten Jembrana, mengidentifikasikan alasan petani kakao mengikuti program sertifikasi UTZ. Analisis data yang digunakan adalah menghitung pendapatan usahatani, uji beda (uji-t) dan analisis deskriptif kualitatif. Hasil penelitian menunjukkan rata-rata produktivitas usahatani kakao bersertifikat UTZ sebanyak 173,20 kg/ha dan non sertifikat sebanyak $211,88 \mathrm{~kg} / \mathrm{ha}$, yang menunjukkan bahwa produksi kakao bersertifikat UTZ lebih rendah sebesar 22,3\% dibandingkan dengan non sertifikat. Pendapatan Usahatani bersertifikat UTZ lebih tinggi $45,17 \%$ yaitu sebesar Rp 4.887.639/ha/tahun dibandingkan dengan petani non sertifikat yang hanya memperoleh Rp 2.676.833/ha/tahun. Usahatani kakao bersertifikat UTZ memiliki R/C sebesar 3,3 sedangkan petani kakao non sertifikat UTZ sebesar 1,9. Hal ini menunjukkan bahwa usahatani kakao bersertifikat lebih menguntungkan dibandingkan dengan usahatani kakao non sertifikat. Tiga alasan utama petani mengikuti program sertifikasi UTZ adalah adanya sosialisasi pengenalan program sertifikasi, mendapatkan harga jual yang tinggi.
\end{abstract}

Kata Kunci: Pendapatan Petani, Usahatani Kakao, UTZ Certified

\begin{abstract}
Indonesia is the third cocoa producer in the world. Indonesian cocoa commodity is very important to be developed in terms of quantity but in terms of quality of approval is still low for the European special world market The program that can encourage the production and quality of cocoa is through sustainable agriculture certification by UTZ Certified. One of the UTZ certificate holders in Indonesia is Kerta Semana Samaniya Cooperative in Jembrana Regency. The purpose of this study was to study the differences in production and income of cocoa farming, UTZ certification and those who did not receive the UTZ certificate program in Jembrana Regency, identifying the reasons farmers received the UTZ certification program. Analysis of data used farm income calculation, t-test and qualitative
\end{abstract}


descriptive analysis. The results showed that the average productivity of UTZ certified cocoa farming was $173.20 \mathrm{~kg} / \mathrm{ha}$ and non-certificates $211.88 \mathrm{~kg} / \mathrm{ha}$, which showed UTZ certified cocoa production was lower by $22.3 \%$ compared to non-certificates. Farming income approved by UTZ was $45.17 \%$ higher, which amounted to Rp.4,887,639 / ha / year compared to non-certified farmers who only received Rp.2,676,833 / ha / year. UTZ approved cocoa farming has $R$ / C of 3.3 while non-certificates cacao farmers are 1.9. This shows that cocoa farming is more profitable than cacao farming is not a certificate. The three main reasons for participating in the certification program, UTZ are introduction socialization program, getting high price and market.

Keywords: Cocoa Farming, Revenue, UTZ Certified

\section{PENDAHULUAN}

Komoditi kakao merupakan andalan dari komoditi perkebunan dalam menghasilkan devisa negara, sumber pendapatan dan mendorong agroindustri Indonesia menciptakan lapangan kerja dan mendorong pengembangan pengelolaan sumberdaya alam daerah. Menurut Food and Agricultural Organitation (2013) Indonesia merupakan penghasil kakao tebesar ketiga didunia setelah Pantai Gading dan Ghana. Pada tahun 2016 komoditas unggulan kakao mencapai kinerja sebesar Rp 26.272,69 milyar dengan jumlah produksi 656.817 ton dan luas areal 1.701.351 ha (Ditjen Perkebunan, 2016).

Komoditi kakao Indonesia sangat berpotensi untuk dikembangkan dari segi kuantitas namun dari segi kualitas dinilai masih rendah untuk pasar dunia terutama Eropa. Hal ini disebabkan karena mutunya rendah dan tidak difermentasi sehingga harganya dikenakan automatic detention, terutama di pasar Amerika Serikat yang merupakan negara tujuan ekspor biji kakao terbesar kedua setelah Malaysia (Hasibuan, 2012). Data Direktorat Jenderal Perkebunan Kementrian Pertanian (2012) bahwa pada tahun 2010 biji kakao Indonesia mendapat potongan harga \$US 500/ton. Aturan ini sangat merugikan karena negara produsen harus menanggung beban yang timbul dari penerapan aturan tersebut (Wahyudi, 2009).

Salah satu cara yang dapat mendukung petani meningkatkan mutu biji kakao yang memiliki daya saing tinggi yaitu melalui peningkatan perhatian terhadap lingkungan, sosial dan ekonomi dengan sistem pertanian berkelanjutan. Perhatian tersebut dapat didukung dengan adanya program sertifikasi atau label pertanian berkelanjutan (CSP, 2012). Hal ini berfungsi untuk memastikan proses produksi biji kakao berlabel dari hulu sampai hilir sudah mengikuti rantai pasokan (suply chain) berdasarkan aturan-aturan pertanian berkelanjutan yang disepakati secara Internasional (UTZ,2016). Salah satu label dan program sertifikasi pertanian berkelanjutan yang telah berjalan di Indonesia adalah UTZ.

Salah satu pemegang sertifikasi UTZ komoditi Kakao yang ada di wilayah Provinsi Bali adalah Koperasi Kerta Semana Samiya (KSS). KSS merupakan sebuah koperasi yang bergerak dalam manajemen dan pemasaran kakao di Kabupaten Jembrana. Dampak yang dirasakan oleh petani kakao yaitu pembenahan manajemen koperasi, pedoman prilaku dari UTZ berguna sebagai pedoman dalam mengontrol petani berproduksi secara pertanian berkelanjutan, posisi tawar terhdap harga dan pilihan pasar lebih kuat.

Penerapan program sertifikat UTZ di Kabupaten Jembrana menghadapi berbagai permasalahan yaitu ketersediaan dana untuk melakukan pelatihan petani secara berkelanjutan, ketersediaan modal belum maksimal untuk membeli biji kakao petani, dan belum semua produksi kakao basah dari petani dapat diolah ditingkat Unit Pengolahan Hasil (UPH) subak karena standar kualitas (Kalimajari, 2015). Berbagai permasalahan tersebut menimbulkan pertanyaan apakah program ini mampu diikuti oleh petani kakao dan memberikan manfaat seperti meningkatkan produksi dan pendapatan petani kakao di Kabupaten Jembrana. 
Hal ini menarik untuk dikaji tentang peranan program UTZ Certified terhadap peningkatan produksid dan pendapatan petani kakao di Kabupaten Jembrana. Penelitian ini bertujuan untuk mengidentifikasi perbedaan produksi, mengidentifikasi pendapatan usahatani kakao bersertifikat dan non sertifikat serta mengidentifikasi alasan mengikuti program sertifikat UTZ.

Penelitian yang dilakukan oleh Oseni dan Adams (2013) yaitu tentang analisa biayamanfaat produksi kakao bersertifikat di Ondo State, Nigeria. Hasil penelitian ini menunjukkan bahwa produksi kakao yang bersertifikat lebih menguntungkan daripada produksi kakao konvensional. Total biaya produksi kakao secara konvensional lebih kecil daripada produksi kakao bersertifikat. Kendala utama yang diidentifikasi dalam produksi kakao bersertifikat adalah sumber daya yang tidak memadai untuk biaya operasi pertanian dan input yang tidak tersedia.

\section{METODE PENELITIAN}

Penelitian ini dilaksanakan pada tanggal 21 Agustus 2018 sampai dengan 29 Oktober 2018 di Kabupaten Jembrana. Pemilihan lokasi ditentukan dengan purposive, dengan pertimbangan yaitu petani kakao yang mengikuti program sertifikat UTZ di Provinsi Bali hanya Kabupaten Jembrana dan juga merupakan sentra produksi tanaman kakao tebesar di Provinsi Bali yang memiliki keadaan tanah dan iklim yang sesuai dengan tanaman kakao. Pengumpulan data dilakukan dengan menggunakan wawancara langsung menggunakan panduan kuesioner, observasi dan dokumentasi.

Jenis data yang digunakan adalah jenis data kuantitatif dan data kualitatif. Data kuantitatif dalam penelitian ini adalah harga, biaya tetap, biaya variabel dalam usahatani kakao di Kabupaten Jembrana. Data kualitatif pada penelitian ini adalah gambaran umum daerah penelitian, proses sertifikasi UTZ, alasan petani mengikuto program sertifikasi UTZ. Populasi pada penelitian ini terbagi atas dua yaitu populasi petani kakao yang mengikuti program sertifikasi UTZ di Kabupaten Jembrana. Teknik pengambilan ukuran sampel dalam penelitian ini diambil berdasarkan pertimbangan Frankel dan Wallen (1993) bahwa jumlah sampel penelitian kausal perbandingan sebanyak 30 sampel untuk setiap group. Menurut Gay dan Diehl (1992) berpendapat bahwa ukuran sampel yang dapat diterima pada penelitian kausal-perbandingan sebanyak 30 subyek per group. Berdasarkan pertimbanagan syarat minimum penelitian perbandingan maka jumlah sampel yang digunakan sebanyak 30 sampel petani kakao bersertifikat UTZ dan untuk membandingkan dengan petani nonsertifikat maka diambil 30 sampel petani kakao nonsertifikat di Kabupaten Jembrana. Teknik pemilihan sampel dilakukan dengan metode proporsional sample.

Variabel yang digunakan pada penelitian ini adalah jumlah produksi kakao Koperasi KSS, pendapatan usahatani kakao bersertifikat UTZ dan nonsertifikasi serta alasan petani kakao mau mengikuti program sertifikasi UTZ. Indikator yang digunakan pada jumlah produksi adalah jumlah produksi koperasi KSS per tahun dengan parameter pengukuran $\mathrm{kg} /$ tahun. indikator pendapatan usahatani kakao yang digunakan adalah penerimaan, biaya tetap, biaya variabel dengan parameter pengukuran Rp/tahun. Indikator alasan petani kakao mau mengikuti program sertifikasi UTZ adalah informasi, ekonomi, teknik usahatani, Lingkungan dan sosial.

Metode Analisis data pada penelitian ini adalah analisis pendapatan, $\mathrm{R} / \mathrm{C}$, t-test independen dan analisis kualitatif. Analisis pendapatan usahatani kakao dilakukan dengan menggunakan rumus sebagai berikut (Soekartawi, 2003).

$$
\begin{aligned}
& \mathrm{TC}=\mathrm{TFC}+\mathrm{TVC} \\
& \mathrm{TR}=\mathrm{Y} \times \mathrm{P} \\
& \Pi=\mathrm{TR}-\mathrm{TC}
\end{aligned}
$$

Keterangan:

$\mathrm{TC}=$ Total cost Usahatani kakao dalam tiga tahun $(\mathrm{Rp})$ 
TFC = Total biaya tetap usahatani kakao dalam tiga tahun (Rp)

$\mathrm{TVC}=$ Total biaya variabe dalam tiga tahun (Rp)

TR = Total penerimaan usahatani kakao dalam tiga tahun $(\mathrm{Rp})$

$\mathrm{Y}=$ Jumlah Produksi dalam tiga tahun $(\mathrm{Kg})$

Py = Harga Produksi kakao yang diterima petani kakao ( $\mathrm{Rp} / \mathrm{Kg}$ )

$\pi \quad=$ Pendapatan bersih dalam tiga tahun (Rp)

Analisis perbedaan produksi dan pendapatan usahatani kakao yang bersertifikat UTZ dan non sertifikat dianalisis melalui ttest sampel independen. Uji-t dilakukan menggunakan nilai signifikansi sebesar $0,05 \%$. Analisis kualitatif dengan pendekatan deskriptif kualitatif untuk menganalisis alasan petani kakao mengikuti program sertifikasi UTZ.

\section{HASIL DAN PEMBAHASAN}

\section{Produksi Biji Kakao Sertifikasi UTZ dan Biji Kakao Non sertifikat}

Hasil produksi usahatani kakao dihitung selama tiga tahun yaitu dari tahun 2015 sampai tahun 2017. Rata-rata usia pohon kakao bersertfikat dalam satu lahan memiliki berbagai usia pohon dan usia pohon kakao pada usaha tani nonsertifikat 20-33 tahun. Petani kakao bersertifikat memiliki luas garapan 34,9 hektar dan kakao nonserifikat memiliki luas garapan 29,9 hektar. Rata-rata jumlah pohon kakao bersertifikat adalah 501 pohon dan 523 pohon kakao nonsertifikat per ha. Tabel 1.1 menunjukkan perbedaaan hasil produksi kakao bersertifikat dan nonsertifikat di Kabupaten Jembrana.

Dilihat dari Tabel 1.1 bahwa jumlah produksi selama tiga tahun terakhir kakao bersertifikat UTZ lebih tinggi dari usahatani kakao nonsertifikat UTZ yaitu jumlah produksi kakao bersertifikat UTZ sebesar $18.129,24 \mathrm{~kg}$ dan produksi kakao nonsertifikat UTZ sebesar 14.588 dengan selisih $3.541,24 \mathrm{~kg}$. Kondisi ini berbeda jika dilihat dari rata-rata produktivitas usahatani kakao bersertifikat UTZ sebanyak 173,20 $\mathrm{kg} / \mathrm{ha}$ dan non sertifikat sebanyak 211,88 $\mathrm{kg} / \mathrm{ha}$, yang menunjukkan bahwa produksi kakao bersertifikat UTZ lebih rendah sebesar 22,3\% dibandingkan dengan non sertifikat.

Perbedaan jumlah produksi usahatani kakao bersertifikat lebih rendah daripada nonsertifikat disebabkan oleh pertama karena tanaman kakao bersertifikat UTZ wajib melakukan peremajaan sedangkan petani kakao nonsertifikat tidak melakukan peremajaan walaupun kondisi tanaman kakao yang sudah tua yaitu rata-rata berumur 20 tahun. Peremajaan dilakukan dengan metode sambung samping dan replanting. Dampak dari peremajaan akan menyebabkan penurunan produksi karena membutuhkan waktu satu sampai dua tahun untuk kakao dapat berproduksi kembali. Peremajaan dilakukan untuk menggantikan pohon yang relative tua dan mengganti klon lama ke variates yang baru sehingga produksi

Tabel 1.1 Hasil Produksi Biji Kakao Tahun 2015-2017

\begin{tabular}{ccccc}
\hline \multirow{2}{*}{ Tahun } & \multicolumn{2}{c}{ Bersertifikat } & \multicolumn{2}{c}{ Nonsertifikat } \\
\cline { 2 - 5 } & Produksi (Kg) & Produktivitas (kg/ha) & $\begin{array}{c}\text { Produksi } \\
(\mathrm{Kg})\end{array}$ & Produktivitas (kg/ha) \\
\hline 2015 & $5.746,24$ & 164,70 & $4.819,00$ & 209,98 \\
2016 & $5.291,00$ & 151,65 & $4.590,00$ & 200,00 \\
2017 & $7.092,00$ & 203,27 & $5.179,00$ & 225,66 \\
\hline Jumlah & $18.129,24$ & & $14.588,00$ & \\
\hline Rata-rata & $6.043,08$ & 173,206 & $4.862,67$ & 211,88 \\
\hline
\end{tabular}

Sumber: Data Primer 2018 Diolah 
diharapkan akan meningkat. Variates lama yang sebelumnya ditanam yaitu jenis kakao lindak sebagian besar telah diremajakan dan diganti dengan klon yang lebih tahan penyakit dan tingkat produksi tinggi yaitu klon Sulawesi dan panther. Hal ini sejalan dengan penelitian Anwar (2014) bahwa kegiatan rehabilitasi tanaman kakao menyebabkan turunya produksi tanaman, sehingga memerlukan waktu sekitar 3-5 tahun agar tanaman dapat kembali berproduksi secara optimal. Penelitian Rinaldi (2013) bahwa peremajaan atau rehabilitasi tanaman kakao perlu dilakukan bagi petani yang ingin meningkatkan produksi kakao.

Penyebab kedua adalah petani bersertifikat UTZ telah melakukan pengurangan penggunaan bahan kimia dan lebih kesistem organik sedangkan petani kakao nonsertifikat menggunakan pertanian secara konvensional seperti penggunaan pestisida kimia dan pupuk kimia. Berdasarkan pengamatan dilapangan baik tanaman kakao bersertifikat maupun nonsertifikat menghadapi permasalahan yang sama yaitu serangan hama, penyakit penggerek buah kakao (PBK) dan busuk buah kakao yang berpotensi menurunkan produksi kakao. Penelitian Rinaldi (2013) mengungkapkan bahwa penggunaan pestisida diduga berpengaruh nyata dengan peningkatan produksi kakao. Pengurangan penggunaan bahan kimia dan menggunakan bahan organik belum mampu meningkatkan produktivitas karena penggunaan bahan organic membutuhkan waktu yang relatif lebih lama dalam membasmi hama berbeda dengan penggunaan bahan kimia relatif lebih cepat. Hal ini sejalan dengan yang penelitian Oktami (2014) penggunaan pupuk kimia dan penambahan penggunaan pupuk organik dalam usahatani kopi petani yang mengikuti program sertifikasi belum menunjukan peningkatan produksi kopi yang signifikan. Hal ini dikarenakan, manfaat penggunaan pupuk organik memiliki dampak peningkatan produksi yang membutuhkan kurun waktu relatif lama.
Berdasarkan hasil uji t-test data total produksi kakao memiliki nilai signifikansi sebesar $0,259>0,05$ dapat disimpulkan bahwa tidak ada perbedaan rata-rata yang signifikan data total produksi antara bersertifikat dan nonsertifikat. Kondisi dimana usahatani kakao bersertifikat memiliki produktivitas lebih rendah dibandingkan dengan usahatani kakao non sertifikat menunjukkan bahwa peningkatan produktivitas yang mengikuti program sertifikasi UTZ belum terlihat mengalami peningkatan. Namun demikian jika dilihat dari penyebab penurunan produksi yang dilakukan untuk perencanaan untuk manfaat peningkatkan produksi dalam jangka panjang. Hal ini menunjukkan bahwa program sertifikat UTZ berpotensi meningkatkan produktivitas kakao tetapi membutuhkan waktu beberapa tahun dimulai dari tahun pertama mengikuti program sertifikasi.

Hasil ini berbeda dengan penelitian Ingram (2014) bahwa petani bersertifikat UTZ dan peserta program UTZ memperoleh hasil panen yang lebih tinggi secara signifikan per hektar rata-rata $(467 \mathrm{~kg} / \mathrm{ha})$ dibandingkan petani non-bersertifikat dan kelompok kontrol (315 kg / ha) di Pantai Gading. Peningkatan hasil adalah sebagian besar disebabkan oleh pelatihan Good Agriculture Practice. Namun demikian pada penelitian selanjutnya Ingram (2018) menemukan bahwa tidak ada perbedaan tingkat produktivitas serta perubahan dari waktu ke waktu antara petani bersertifikat UTZ dan non sertifikat di Ghana namun berbeda dengan wilayah Pantai Gading, petani kakao bersertifikat UTZ memiliki produksi yang lebih tinggi secara significant dibandingkan dengan non sertifikat. Secara umum produktivitas petani kakao bersertifikat UTZ maupun non sertifikat tergolong rendah yaitu dengan rata-rata produksi $321 \mathrm{~kg} / \mathrm{ha}$ di Ghana dan 480 kg/ha di Pantai Gading.

Penelitian Anwar (2014) Kehadiran program NCP belum terbukti berdampak pada upaya peningkatan produktivitas dan penerimaan petani kakao. Jika dikelompokkan berdasarkan umur tanaman, 
terjadi peningkatan produktivitas pada kelompok tanaman produktif. Nilai peningkatan produktivitas mencapai 155.35 $\mathrm{kg} / \mathrm{ha}$ /tahun. Namun, peningkatan produktivitas pada kelompok ini dibarengi dengan peningkatan jumlah tanaman produktif sebelum adanya program NCP. Adanya program NCP memberikan dampak positif dalam menggambarkan potensi peningkatan produksi dan produktivitas tanaman kakao di Sulawesi Barat.

\section{Pendapatan Usahatani Kakao di Kabupaten Jembrana}

Penerimaan petani kakao bersertifikat UTZ sebesar Rp 734.348.976 sedangkan petani kakao nonsertifikat UTZ sebesar $\mathrm{Rp}$ 384.238.000. Selisih rata-rata penerimaan dalam satu ha sebesar $\mathrm{Rp} 1.435 .050,58$ dimana penerimaan petani kakao bersertifikat UTZ lebih tinggi yaitu sebesar Rp 7.015.849,58 per ha sedangkan penerimaan kakao nonsertifikat sebesar Rp 5.580.799 per ha. Total biaya usahatani kakao bersertifikat lebih kecil dibandingkan usahatani kakao nonsertifikat yaitu dengan selisih Rp 23.028.309 tetapi bila dilihat dari rata-rata biaya per $\mathrm{kg}$ dan per ha kakao bersertifikat lebih kecil dari nonsertifikat. Biaya usahatani kakao bersertifikat UTZ sebesar Rp 222.759.809 yang berarti biaya per ha dan biaya per $\mathrm{kg}$ adalah sebesar Rp 1.506.487 dan Rp 11.002 sedangkan usahatani kakao nonsertifikat mengeluarkan biaya sebesar Rp 199.731.500 yang berarti biaya perhektar dan biaya per $\mathrm{kg}$ adalah sebesar Rp 2.900.966 dan Rp 13.729,66. Biaya per ha usahatani kakao bersertifikat UTZ lebih kecil $48 \%$ daripada usahatani kaka nonsertifikat begitu juga dengan biaya per kg usahatani kakao bersertifikat UTZ lebih kecil $24,7 \%$ daripada biaya per $\mathrm{kg}$ usahatani kakao nonsertifikat. Hal ini senada dengan penelitian Ingram (2014) petani bersertifikat UTZ dan peserta program memiliki biaya produksi per kilogram secara signifikan lebih rendah dibandingkan dengan petani kelompok tidak bersertifikat dan kontrol.
Total pendapatan petani kakao bersertifikat UTZ lebih tinggi dibandingkan dengan petani kakao nonsertifikat. Pendapatan usahatani kakao bersertifikat UTZ sebesar Rp 511.589.167 dan usahatani kakao nonsertifikat sebesar Rp 184.506.500. Pendapatan perhektar petani kakao bersertifikat adalah $\mathrm{Rp} 4.887 .639$ dengan presentase sebesar 45,17\% lebih tinggi dibandingkan dengan petani nonsertifikat yaitu Rp 2.679.833. Pendapatan per kg petani bersertifikat UTZ adalah Rp 28.330 dibandingkan dengan petani kakao nonsertifikat $\mathrm{Rp} 12.605$ dengan presentase $55,5 \%$ lebih tinggi pendapatan per $\mathrm{kg}$ petani kakao bersertifikat UTZ.

Berdasarkan hasil uji independent samples $t$ test diketahui bahwa nilai signifikansi atau p-value $0,000<0,05$ sehingga dapat disimpulkan bahwa ada perbedaan rata-rata yang signifikan antara data total pendapatan bersertifikat dengan nonsertifikat. Pendapatan yang diperoleh oleh usahatani kakao bersertifikasi UTZ lebih tinggi daripada nonsertifikasi menggambarkan bahwa program sertifikat UTZ mampu meningkatkan pendapatan petani. Hal ini sejalan dengan penelitian Ingram (2018) bahwa pendapatan per ha dan total pendapatan bersertifikat UTZ lebih tinggi dari pada non sertifikat di Ghana dan Pantai Gading.

\section{Analisis R/C Rasio Usahatani Kakao di Kabupaten Jembrana}

Usahatani kakao bersertifikat UTZ memiliki $\mathrm{R} / \mathrm{C}$ atas biaya lebih tinggi yaitu sebesar 3,3 sedangkan petani kakao nonsertifikat UTZ sebesar 1,9 dimana R/C rasio kedua usahatani lebih besar dari satu, $\mathrm{R} / \mathrm{C}$ rasio lebih besar dari satu sehingga kedua usahatani dikatakan menguntungkan. Lebih tingginya nilai $\mathrm{R} / \mathrm{C}$ rasio petani bersertifikat menunjukkan bahwa dari penggunaan biaya total, usahatani kakao sertifikat lebih menguntungkan dibandingkan dengan usahatani kakao nonsertifikat dalam menghasilkan penerimaan. Implikasinya adalah program sertifikat UTZ mampu 
meningkatkan pendapatan petani kakao di Kabupaten Jembrana Penelitian serupa. Hal ini senada dengan penelitian Oseni dan Adams (2013) bahwa produksi kakao yang bersertifikat lebih menguntungkan daripada produksi kakao konvensional di Ondo State, Nigeria. Ingram (2018) mengungkapkan bahwa terjadi peningkatan pendapatan yang signifikan dialami oleh petani sertifikat UTZ yang melakukan seluruh rangkaian dari layanan UTZ di Pantai Gading dan Ghana. Namun dari jenis dan intensitas layanan sertifikat yang berubah dari waktu ke waktu berdampak kepada penurunan jumlah partisipasi petani serta produksi dan pendapatan yang tidak signifikan.

\section{Alasan Petani Mau Mengikuti Program Sertifikasi UTZ}

Tiga alasan utama petani mengikuti program sertifikasi UTZ adalah adanya sosialisasi pengenalan program sertifikasi, mendapatkan harga jual yang tinggi kemudian diikuti dengan mendapatkan pelatihan, meningkatkan pengetahuan tentang budidaya kakao, social, tempat berbagi ilmu, melestarikan dan menjaga lingkungan hidup. Program yang disosialisasikan atau perkenalan program dengan petani sangat berperan dalam menumbuhkan minat petani untuk mengikuti program sertifikasi. Petani yang mengikuti program sertifikat UTZ mendapatkan informasi UTZ dari pendamping yaitu Kalimajari. Hal ini untuk menjaring partisipasi petani yang berperan untuk mengikuti program kakao lestari. Pengembangan jumlah partisipasi petani untuk mau mengikuti program ini diperlukan sosialisasi yang lebih gencar agar program ini dapat diketahui oleh calon anggota/ petani kakao yang belum pernah mendengar program ini. Alasan petani mengikuti program sertifikasi terbanyak kedua adalah karena petani ingin mendapatkan harga yang lebih tinggi yaitu sebanyak 29 petani dan kemudian disusul karena adanya jaminan pasar kakao yaitu sebanyak 23 orang. Hal ini menunjukkan bahwa petani kakao mengikuti program mempertimbangkan segi ekonomi merupakan alasan utama petani mau mengikuti sertifikasi ini dengan harapan bahwa dengan mendapatkan harga yang tinggi akan meningkatkan pendapatan petani.

Petani memiliki harapan dengan mengikuti program ini mereka mendapatkan ilmu dari pelatihan-pelatihan yang diberikan untuk mampu meningkatkan kapasitas dalam hal berbudidaya kakao. pelatihan yang diberikan ICS kepada petani adalah penerapan GAP, seperti penggunaan pupuk dan pestisida yang optimal, pelatihan pembuatan kompos organik, serta pelatihan pengembangan teknik grafting untuk menghasilkan bibit yang berkualitas. Peningkatan kemampuan teknik usahatani kakao. Pelatihan rutin yang dilaksanakan menjadi wadah berkumpulnya petani kakao bersertifikat UTZ. Petani menjawab program ini memberikan tempat berdiskusi sebanyak 8 petani. Mereka melihat hal yang menarik dari program ini adalah kelembagaannya yang bisa menjadi wadah selain mendorong produksi kakao. Koperasi Kerta Semana Samaiya dibentuk sebagai wadah tempat berkumpulnya anggota-anggota petani kakao. Penelitian Oktami (2014) juga mengungkapkan bahwa faktor-faktor yang berpengaruh terhadap keputusan petani dalam menerapkan usahatani bersertifikasi Rainforest Alliance adalah pendapatan dan keikutsertaan dalam setiap program sertifikasi.

\section{SIMPULAN DAN SARAN}

Hasil penelitian menunjukkan rata-rata produktivitas usahatani kakao bersertifikat UTZ sebanyak $173,20 \mathrm{~kg} / \mathrm{ha}$ dan non sertifikat sebanyak 211,88 kg/ha, yang menunjukkan bahwa produksi kakao bersertifikat UTZ lebih rendah sebesar 22,3\% dibandingkan dengan non sertifikat. Uji sampel t-test untuk data total produksi kakao nilai sig $0,259>0,05$ bahwa tidak ada perbedaan rata-rata yang signifikan antara data total produksi antara bersertifikat dan nonsertifikat. Kondisi ini menunjukkan bahwa peningkatan produktivitas yang 
mengikuti program sertifikasi UTZ belum terlihat mengalami peningkatan tetapi memiliki potensi untuk meningkatkan produktivitas kakao tetapi membutuhkan waktu beberapa tahun dimulai dari tahun pertama mengikuti program sertifikasi.

Pendapatan Usahatani bersertifikat UTZ lebih tinggi $45,17 \%$ yaitu sebesar Rp 4.887.639/ha/tahun dibandingkan dengan petani non sertifikat yang hanya memperoleh Rp 2.676.833/ha/tahun. Usahatani kakao bersertifikat UTZ memiliki R/C sebesar 3,3 sedangkan petani kakao non sertifikat UTZ sebesar 1,9. Hal ini menunjukkan bahwa usahatani kakao bersertifikat lebih menguntungkan dibandingkan dengan usahatani kakao non sertifikat dan menggambarkan bahwa program sertifikat UTZ mampu meningkatkan pendapatan petani. Tiga alasan utama petani mengikuti program sertifikasi UTZ adalah adanya sosialisasi pengenalan program sertifikasi, mendapatkan harga jual yang lebih tinggi dibandingkan dengan tanpa sertifikasi dan adanya jaminan pasar.

Berdasarkan hasil penelitian dan keadaan lapangan maka saran dari penelitian ini adalah pemerintah sebaiknya lebih mensosialisasikan kepada petani kakao manfaat dan keuntungan program sertifikasi untuk meningkatkan keterampilan dan pendapatan petani kakao di Kabupaten Jembrana. Koperasi KSS hendaknya menempatkan seorang yang ahli dalam bidang agronomi yang ditempatkan dalam struktur Internal Control System agar dapat melatih petani tentang ilmu-ilmu pertanian dan memahami keadaan lapangan kakao Jembrana untuk meningkatkan produktivitas kakao di Kabupaten Jembrana. Masa sertfikasi UTZ sebaiknya diperpanjang karena masa satu tahun terlalu singkat untuk persiapan memenuhi standar yang ada didalam COC UTZ.

\section{DAFTAR PUSTAKA}

Anwar, H. 2014. Analisis Kapasitas Kelembagaan dan Penerimaan Petani Anggota Poktan Program Nestle
Cocoa Plan Pisagro. Skripsi. Program Sarjana Institut Pertanian Bogor, Bogor.

Chairawaty, F. 2012. Dampak pelaksanaan perlindungan lingkungan melalui Sertifikasi Fair Trade (studi kasus: petani kopi anggota Koperasi Permata Gayo, Kabupaten Bener Meriah, Nangroe Aceh Darusalam. Jurnal Ilmu Lingkungan UNDIP. 10(2) : 76-84.

Direktorat Jenderal Perkebunan., Kementrian Pertanian. 2013. Statistik Perkebunan Tahun 2008-2012. http://ditjenbun.dep tan.go.id Diakses tanggal 09 Mei 2019

FAO. 2013. Assets Infograpich Chocolate. United Nations. Food Agriculture Organitation. www.fao.org Diakses tanggal 21 November 2017

Fraenkel, J. dan N. Wallen. 1993. How to Design and evaluate research in education, 2nd Ed. McGraw-Hill Inc, New York.

Gay, L. R. and P. L. Diehl. 1992. Research Methods for Business and Management. Mc. Millan Publishing Company, New York.

Hasibuan, A. M. 2012. Model System Dinamis Pengembangan Agroindustri Kakao Tesis. Program Pasca Sarjana Institut Pertanian Bogor, Bogor.

Hasibuan, A. Analisis Kinerja Dan Daya Saing Perdagangan Biji Kakao Dan Produk Kakao Olahan Indonesia Di Pasar Internasional. Jurnal Buletin RISTRI. 3(1) : 57-69.

Ingram V. van Rijn F. waarts Y. Gilhuis $\mathrm{H}$. 2018. The Impacts of Cocoa Sustainability Initiatives in West Africa. LEI Wageningen UR. Den Haag, The Netherlands.

Ingram V., Waarts Y, Ge L., van Vugt S., Wegner L., Puister-Jansen L., Ruf F., Tanoh R. 2014. Impact of UTZ Certification of cocoa in Ivory Coast 
Assessment framework and baseline. LEI Wageningen UR. Den Haag, The Netherlands.

Juwita T. 2013. Manfaat pembinaan dan verifikasi kopi dalam upaya peningkatan mutu kopi (Studi Kasus: Program Verifikasi Binaan PT Nestlé Indonesia di Kabupaten Tanggamus). JIIA. 2(3) : 276-284.

Kalimajari. 2015. Laporan Participatory Action Research Kalimajari. Yayasan Kalimajari. Bali

Oktami, N. 2014. Manfaat Sertifikasi Rainforest Alliance (RA) dalam Mengembangkan Usahatani Kopi yang Berkelanjutan di Kecamatan Pulau Panggung Kabupaten Tanggamus. Skripsi. Program Sarjana Universitas Lampung, Bandar Lampung.

Oseni, O. Joseph, dan A. Q. Adams. 2013. Cost Benefit Analysis of Certified Cocoa Production in Ondo State. Invited paper presented at the 4th International Conference of the African Association of Agricultural Economists. Nigeria: Federal University Of Technology.

Rahayu, Y. 2014. Perencanaan Usaha Tani Berkelanjutan Berbasis Kakao Di Sub Das Way Semah Provinsi Lampung. Tesis. Program Pascasarjana Institut Pertanian Bogor, Bogor.

Rinaldi, J. 2013. Faktor-faktor yang mempengaruhi produksi kakao pada perkebunan rakyat di Bali: Pendekatan Stochastic Frontier. J. Sepa : 10 (1): 47 -54 .
Saragih, J. F. 2013. Socioeconomic and ecological dimension of certified and conventional arabica coffee production in North Sumatra, Indonesia. Asian Journal of Agriculture and Rural Development: 3(3): 93-107.

Sari, D. M. 2017. Efisiensi Produksi dan Pendapatan Usahatani Kakao Rakyat Di Provinsi Lampung. Tesis. Program Pascasarjana Institut Pertanian Bogor, Bogor.

Soekartawi. Soeharjo. Dillon, JL. Hardaker, JB. 1984. Ilmu Usahatani dan Penelitian untuk Pengembangan Petani Kecil. UI Press, Jakarta.

Tresliyana, A. Fariyanti. Riffin. 2015. Daya saing kakao Indonesia di pasar internasional. J. Manajemen dan Agribisnis. 12 (2): 150-161.

UTZ. 2015. Pedoman Perilakui inti versi 1.1. Amsterdam:UTZ

Wahyudi, T., Pangabean, dan R. Pujiyanto. 2009 Panduan Lengkap KakaoManajemen Agribisnis dari Hulu Hingga Hilir. Penebar Swadaya, Jakarta. 